\title{
(1) $l-3398$
}

UCID- 18798

MFIF-B PHYSICS REQUIREMEATS

3. D. Porter

R. I. Thomassen

March 25, 1981

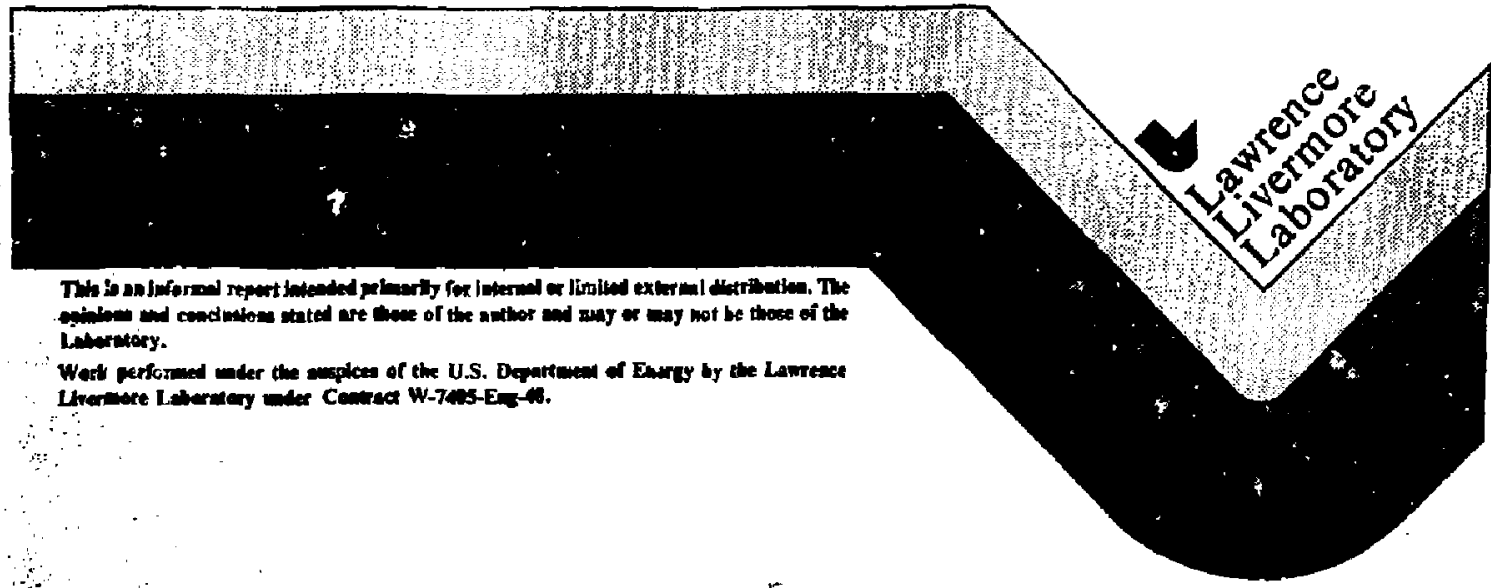

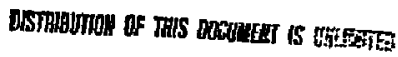




\title{
MFTF-B PHYSICS REQUIREMENTS
}

\author{
G. D. Porter
}

K. I. Thomassen

\section{INTRODUCTION}

The Hirror Fusion Test Facility (MFTF) is a $\$ 96.2$ million constructior project at Lawtence Livermore National Laboratory (LLNL) scheduled for FY 78-81. This single-cell mirror facility was proposed in March 1976 to explore scaling laws and to advance the technology of mirror fusion devices. We have

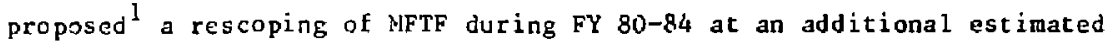
cost of $\$ 122.4 \mathrm{milli}$ on in plant-and-capital-equipment (PACE) funds. This upgrade, called MFTF-B, will convert the facility to a large tanden mirror configuration, which is now the mainline approach to a mirror fusion reactor. Our plan is to proceed directly to the tandem configuration without first operating HFTF in the single-cell mode.

The evolution of the mirror program frow single-cell to tandem magnetic configurations is a recent one, not envisioned when MFTF was proposed and accepted. However, from the outset it was intended that means be sought to enhance the Eusion-power-gain factor $Q$ and that the MFTF project maintain sufficient flexibility to incorporate the best ideas developed after the project was initiated. As the full advantage of the tandem mirror approach to Q-enhancement became evident, ILNL began a survey of several possible plans for advancing the physics of the candem mirror concept beyond what could be learned in the Tandem Mirror Experiment (TMX) then under construction. Among those plans, the modification of MFTF to a tandem geometry was considered the most expeditious, cost effective, and promising for advancing the mirror approach.

Essentially, all components of MFTF will be utilized in converting to a tandem configuration. A tandem mirror consists of a long solenoid with "end plugs" tiat create ambipolar potentials to confine ions in the solenoid. In MFTF-B, the yin-yang magnet and vacuum vessel now under construction for MFTF will be utilized (with modifications) on one end, and a duplicate set will be constructed to serve as the other end. In addition, it will be necessary to 
construct the solenoidal section, planned to be about 30m long, and "auxiliary cells" (A-cells) on each end to provide for thermal-barrier operation.

The purpose of this document is to specify the fundamental physics requirements of the MFTF-B. More detailed system requirsments will follow from these physics requirements. In Sec. II of this document, we briefly describe the MFTF-B objectives. In Sec. III we describe the required operating modes of the facility as well as some desirable modes that are less well-defined. In Sec. IV we define the experimental configuration for these operating modes. Finally, in Sects. V chrough VIII we specify the physics requirements for the magnetic fields, diagnostics, particle and energy sources, and vacuum envi ronment.

\section{I1. MFTF-B OBJECTIVES}

The MFTF-B is the major scaling experiment for the tandem mirror concepi and will provide the physics and technolegy data base necessary for the design of a D-T burnin ${ }_{\vec{E}}$ candem mirror facilicy planned tor construction during the mid 1980 's.

The specific physics objectives for MFTF-B are:

(1) Demonstrate the improvement in Q with inereasing potential well depth, in the range of $0,1<Q<1$.

(2) Explore radial transport in the central cell and determine its influence on confinement.

(3) Explore microinstabilities in the end plugs and means of controlling them.

(4) Explore the B-limits imposed by magnetohydrodynamic (MHD) stability.

The specific technology objectives for MFTF-B are:

(1) To gain experience in constructing and operating a large Nb-Ti superconducting-magnet system.

(2) To learn to construct and operate reliable, long-pulsed, high-current, high-voltage neutral beams.

(3) To maintain high-vacuum condicions in the presence of equilibrium plasma-wall interaetions. 
(4) To handle, without deleterious effects on the plasma or materials of construction, the intense particle and plasma energy deposition on surfaces in the vacuun vessel.

(5) To operate a large fusion facility by a computer control system.

The range of petfornance to be expected from MFTi-B depends critically on the potential difference $\phi_{c}$ between the maximum electrostatic poicntial and the solenoidal contral cell. It is this potential that determines the confinement time of ions in the central cell, according to the approximate relation

$$
n_{c}=7 \times 10^{10} T_{c}^{3 / 2}\left(\phi_{c} / T_{c}\right) \exp \left(\phi_{c} / T_{c}\right),\left(\mathrm{cm}^{-3} \cdot s\right),
$$

where $T_{c}$ is the central-cell ion temperature (keV). Thus, as long as $\phi_{c}$ can be increased in proportion to $T_{c}, n \tau_{c}$ increases as $T_{c}^{3 / 2}$ as in all mirror devices, but with a coeficient that is much more favorable than in a single-cell mirror and becomes even more favorable as $\phi_{c} / T_{c}$ becomes larger. This temperature dependence is illustrated in Fig. 1. Note that the $n$ T operating godls for MFTF-B correspond to $\phi_{c} / T_{c}=2$, which is typical of present operating modes in the Tandem Mirror Experiment (TwX). Of course, $Q$ depends on $n \tau_{c}$ and sensitively on $T_{c}$ through the $D-T$ cross section. The breakeven condition where $Q=1$ is indicated in the figure.

lt is the primary objective of the operating scenarios described below to obtain the highest possible values of $\phi_{c}$ for a given beam energy withi. the plysics constraints of the various operating modes employed, and to map out the performance of the device as a function of $\$$ [item ( 1 ) among the plysics objectives stated above]. How far one can go depends most strongly on the degree of success in obtaining stable operating of all mirror-confined plasmas.

\section{MFTF-B OFrRATING MODES}

\section{A. TWO-COHPONENT STATLARD TANDEM OPERATION}

The most conservative mode of operating MFTF-B will rely on so-called "stream stabilization" of the end plugs, in which the plasma streaming out of 


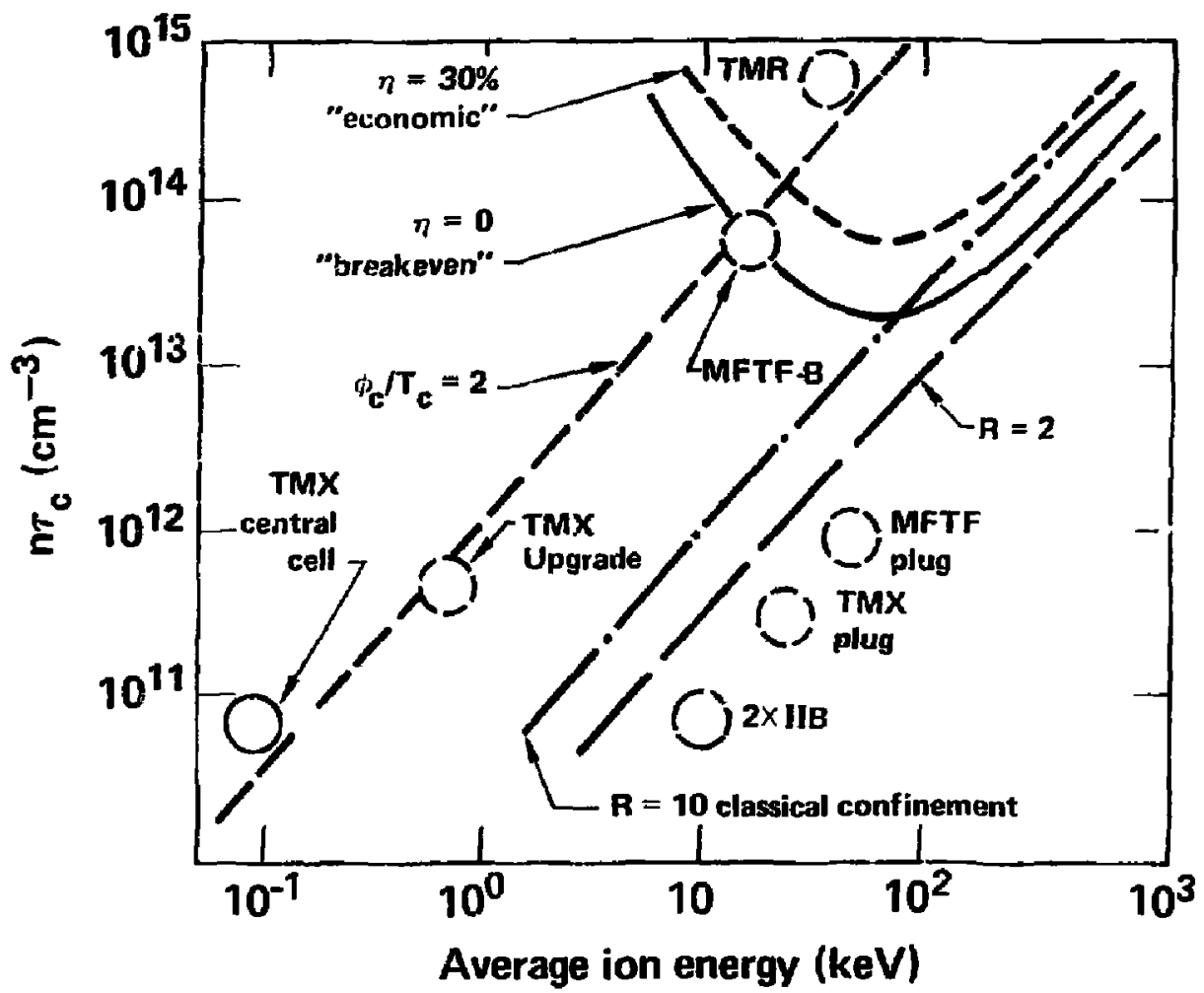

F[G. 1. Product of densicy and particle confinement time for various existing or proposed mirror experiments ( $\eta=$ plant efficiency).

each end of the solenoid provides enough "warm plasma" to fill the ioss cone in velocity space in the mirror-confined plasmas in the end plugs. This stabilization technique works well in TNX, and before that, worked well in the 2 XIIB experiment and elsewhere. Thus, there is essentially no doubt that this teghnique will also work in MFTF-B. This mode of opuration may also serve as the startup phase for high-Q operating modes.

Wich scream stabilization, the electron heat loss is high and, consequent $1 y$, the electron temperature is low. The ion temperature in the central cell typically lies well below the 10 -keV level required for thermonuclear reactors. However, if energetic neutral beams are injested in the central 
cell, the energetic ions depositeu by the beams $c$ an undergo thermonuclear reactions as they slow down by colliding with the colder electrons. If the electron temperature reaches about $5 \mathrm{keV}$, the overall $Q$ of such a system is unity, ard $Q=2$ is possible at higher electron temperatures. The gratest power gain in a reactor would be obtained with pure deuterium beams at an encrgy of 150 to $200 \mathrm{keV}$ injected into a dense, pure-tritium plasma in the crntrat cell. Such a low-Q system, known as a two-component tandem mirror, would be somewhat marginal as a pure fusion reactor but would make a very good fusium-fission hybrjd reactor based on well-understood physics principals that will be tested in TMX and MFTF-B.

By injecting some $80-\mathrm{keV}$ neutral beams into the central cell of MFTF $B$, we can sirmlate a two-component tandem mixror reactor at an electron temperature of $T_{c}=0.7 \mathrm{keV}$. Other plasma parameters are listed in Table 1.

\section{B. HICHH-Q OPEKATTON WLTH THERMAL BARKIERS}

Obtaining higher $Q$ values in MFTF-B requires a change in our approach to stabilizing the mirror-confined plasma in ofder to obtain higler electron temperatures than those obtainable with stream stabilization. This is done by addin? thernal barriers. The main function of the thermal barrier is to thermally insulate the electrons in the end plug from contact with those in the solenoid. The concept is sketched in Fig. 2, which compares the plasma potential profile in the neighborhood of an end plug for the basic tandem configuration (a) and for the tandem mirror with thermal barriers (b). The new ieature is a depression in the potential at the encrance to the end plug. This depression in the posicive potential appears to the negatively charged electrons as a potential barrier and therefore serves as an electrun thermal barrier between the end plugs and the solenoid. If we now heat the electrons in the plug with electron cyclotron resonance heating (ECRH) or other auxiliary heating, the electron tenperature can be much higher there than in the solenoid. With a high electron temperature in the plug, the final potential peak needed to plug up ions laaking from tine solenoid can be generated with a much lower plasma density in the end plug relative to the density in the solenoid. It is this large reduction in plug density that is the advantage of thermal barriers. 
TABLL 1. Approximate parameters for MFTF-B operating scenarios.

\begin{tabular}{|c|c|c|c|}
\hline parameter: & $\begin{array}{l}\text { Two-component } \\
\text { standard tandem } \\
\text { mode }\end{array}$ & $\begin{array}{l}\text { A-cell harrier; } \\
\text { improvsd 80-kV } \\
\text { beams }^{+} \text {(Ref. case) }\end{array}$ & $\begin{array}{l}\text { A-cell barrier; } \\
\text { clean } 80-k V \\
\text { beams }\end{array}$ \\
\hline Q. $(\text { contris cell })^{4}$ & $(\cdot 0.04) \ddagger$ & 0.57 & 1.04 \\
\hline$Q(\text { avera! } 1)^{t+1}$ & & 0.50 & 0.79 \\
\hline$n \cdot c\left(\mathrm{~cm}^{-3} \cdot \mathrm{s}\right)$ & $1.1 \times 10^{12}$ & $5.0 \times 10^{13}$ & $7.5 \times 10^{13}$ \\
\hline$n_{c}\left(\mathrm{~cm}^{-3}\right)$ & $4.3 \times 10^{13}$ & $2.08 \times 10^{13}$ & $1.56 \times 10^{13}$ \\
\hline$T_{c}(s)$ & $3.4 \times 10^{-2}$ & 2.4 & 4.7 \\
\hline$i_{i c}(k e V)$ & 0.15 & 15 & 20 \\
\hline$T_{\text {ec }}(\mathrm{keV})$ & 0.68 & 9 & 12 \\
\hline$\phi_{c}(k e v)$ & 0.43 & 28 & 37 \\
\hline$\phi_{\mathrm{b}}(\mathrm{keV})$ & - & 40 & 60 \\
\hline$\phi_{c}+\phi_{c}(k e v)$ & 4.6 & 85 & 105 \\
\hline$B_{c}$ & 0.17 & 0.2 & 0.2 \\
\hline rp & 0.3 & 0.4 & 0.4 \\
\hline fis & - & 0.3 & 0.3 \\
\hline 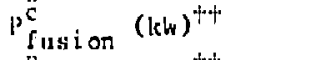 & 0.53 & 915 & 781 \\
\hline$p_{\text {fusion }}^{p}(k w)^{t+t}$ & - & 176 & 110 \\
\hline $\mathrm{P}_{\text {LCKHI }}, 28 \mathrm{GHz}(\mathrm{kW})$ & - & 440 & 159 \\
\hline$P_{E C R H 1}, 56 \mathrm{CHz}(\mathrm{kW})$ & -- & 700 & 310 \\
\hline$I_{i n j}^{c}(A)$ & 211 & 3.0 & 1.4 \\
\hline$I_{i \cap j}^{P}(A)$ & 123 & B.8 & 3.0 \\
\hline$I_{i n j}^{a}(A)$ & - & 1.3 & 0.74 \\
\hline
\end{tabular}

*Vefinitions of the super- and subscripts in this column: a = A-cell, $b=$ thermal barrier, $c=$ central cell, $e=$ electron, $i=i n, p=y i n / y a n g$ cel1, ECRH = electron cyclotron resonance heating, inj $=$ injected.

†'Improved beams: $30-s, 80-k \mathrm{~V}, 80 \% \mathrm{D}^{+}$.

thelean beams: $100 \% 80-k e V$ neutrals.

${ }^{+T}$ As if $D-T$; actual experiments will use pure deuterium.

$\ddagger_{\text {This value of }} Q_{C}$ is limited by the temperature dependence of $\langle\sigma \mathrm{v}\rangle_{\mathrm{DT}}$. For example, if $150-\mathrm{keV}$ beams were injected, rather than $80 \mathrm{keV}$, $Q_{c}$ would rise to 0.1 without significantly changing other plasma parameters. 

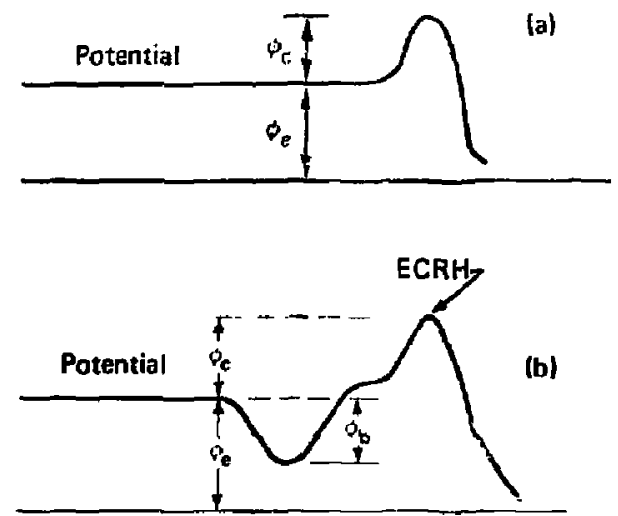

FIC. 2. Comparison between plasma potential profiles: (a) basic tandem potential profile, and (b) potential profile with thermal barriers.

As in the basic tandem configuration (i.e., without thermal barriers), the desired potential profile with thernal barriers is created by manipulating the electron-density profile. To create a potential peak, we create a magnetic mirror region and inject neutral beams to build up a density peak as before. To crate the new feature--the potential depression that produces a thermal barricl-we create another mirror region and depress the density there by pumping .way ions that become mirror-trapped as they pass through this region. In addition, we further depress the potential by intense ECRH in the barrier to create a mirror-trapped electron population there.

One way of implementing a thermal-barrier configuration, called the A-cell barrier, is shown in Fig. 3. This is the basis for the reference case given in Table 1. In this case, both the thermal barrier and the final potential peak are created in the A-cell itself, while mirror-confined ions injected in the yin-yang cell serve mainly to provide MHD stability and to create a small potential peak that reduces the density of passing ions entering the A-cell. To create the A-cell potential profile, ions are injected so that they slosh back and forth in the A-cell, creating peaks in density at their turning points. Application of ECRH heating to the outer densicy peak produces the final potential peak as desired. 


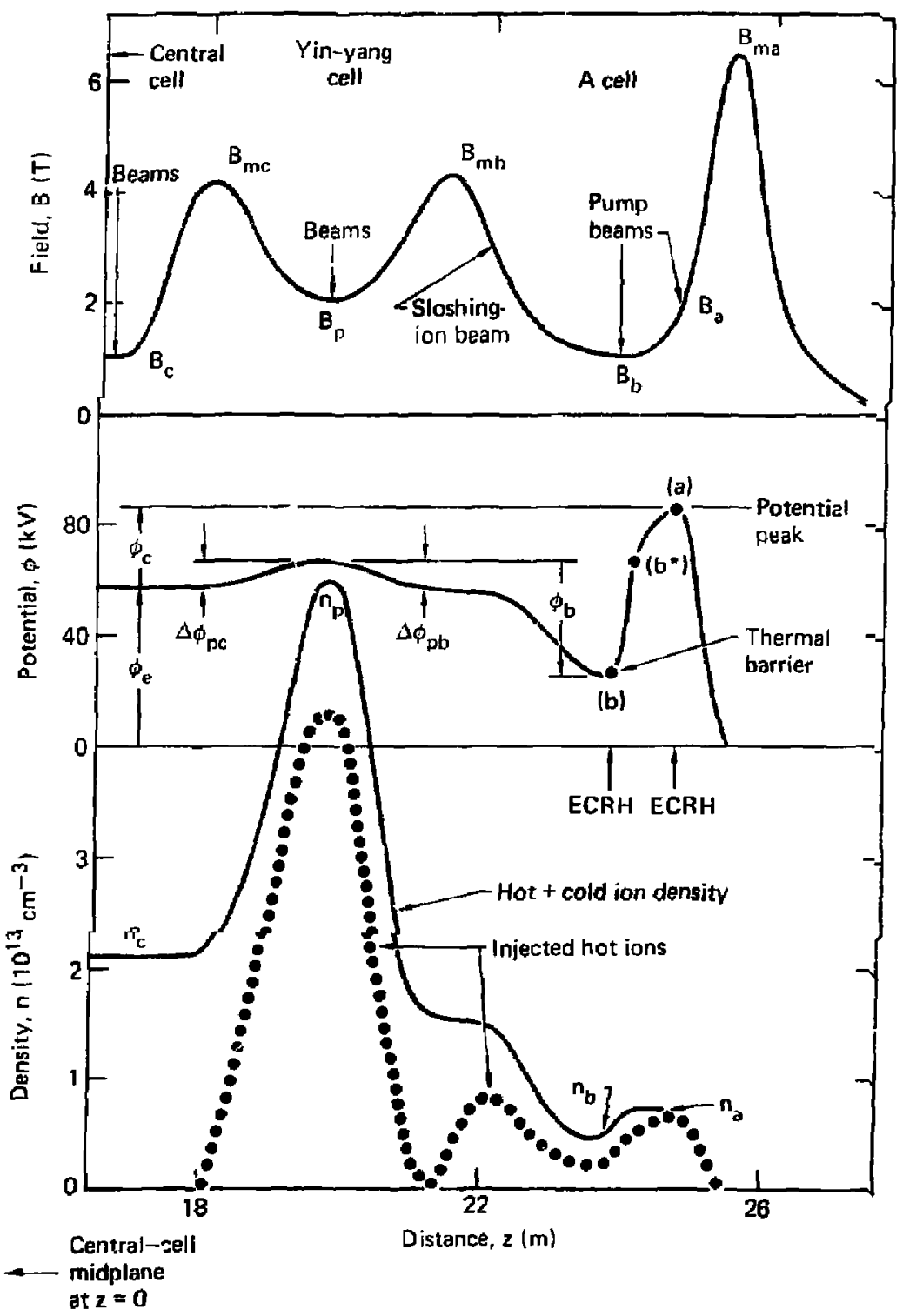

Fla. 3. profiles of fiald $B$, potential $\$$, and censity $n$ versus distance $z$ at one end of :FF'F-B operated with A-ce11-type thermal barriers. 
To maintain the A-cell barrier density profile, it is necessary to pump away ions that become trapped within the barrier potential minimum. In the WHTF-B conceptual design, this pumping is accomplished by charge-exchange interactions between trapped ions and an $80-\mathrm{kV}$ neutral beam. A beam source is located at each end of the machine, and each beam is aimed along the axis so as to pass through both the A-cell and the yin-yang cell. A charge-exchange collision betweer a trapped ion and an axially-aimed neutral swaps a trapped ion for one that is not trapped.

Finally, note that the performance with thermal barriers is sonsitive to the mean energy of the sustaining neutral beams. Two cases are listed in Table 1. The reference case is based on beam sources with a high atomic fraction in the best range of performance achieved thus far with positive-ion sources $\left(20 \%\right.$ of the extracted current is in the molecular ions $\mathrm{D}_{2}^{+}$and $\mathrm{D}_{3}^{+}$, with $80 \%$ in $\left.D_{1}^{+}\right)$. The second case is based on pure $80-\mathrm{kV}$ beams $\left(100 \% \mathrm{D}^{+}\right.$ extracted). Pure $80-k V$ beams might be achieved either by magnetic separation or by negative-ion sources. We have thus far rejected magnetic separation becanse the probability that this method can be developed successfully in the near future is too low. An idez? solution to the problem of improving *is performance of MFTF-B with the presently planned power supplies would be a compact, dire:c-extraction, 80-kV negative-ion source, which would serve as the initial stage of higher-voltage beams that would further improve MFTF-B performance (at 1.50 to $200 \mathrm{kV}$ ) and lead to the still higher-voltage beams that will probably be needed for $D-T$ reactors and certainly for advanced fuels.

\section{OTHER OPERATIMG MODES}

The MFTF-B should be designed to provide a flexible facility for a variety of plasma experiments. The two plasma modes described previously, the standard tandem mode and the thermal-barrier mode, form the basis for the hard requirements that will determine the design. In addition, the compatibility of the machine design with other plasma modes should be considered. In general, thr. Wther modes are not as well understood and hence cannot be used as a jasis of firm design requirements. A design goal for the facility should be that the design will not exclude the possibility of doing experiments with these plasma modes. We expect that machine modification will be necessary before these experiments are done, but that we can minimize the added cost of 
doing such experinents by considering these modes during the initial design of the MFTF-B.

At present, two such plasma mones have been identified. The first, the inside-barrier mode, is cescribed in Ref, 2. The thermal barrier in this mode is created in the yin-yang cell (see Fig. 3) bv establishing a population of mirror-corfined electrons. This is done by ar. . ing ECRH within the yin-yang cell. The plasma pressure in this cell is dominated by thege electrons, and hence they also provide $N$ id stability for the plasma. Neutral beams are not required in the yin-yang cell. The second plasma mode is the field-reversal mode described in Ref. 3. A field-reversed plasma is one with such high internal currents and densities that the direction of the axial field is reversed in the central region around the axis. As ciescribed in Ref, 3 , neutral beams are one proposed means of achieving field reversal, and such an experiments can be done in one of the yin-yang cells or in the rentral cell of MFTF-B.

D. MFTF-B OPERATIONS

The operation cycle for MFTF-B is expected to be the same as that planned for MFTF. Specifically, we expect to operate with an 18-week cycle, during which 13 weeks will be spent running the facility to obtain plasma physics data. The remaining 5 weeks will be used for maintenance and to reconfigure the facility in preparation for the next experimental cycle.

During the 13 week experimental running period, we expect to operate the facility 24 hours a day, using three shifts: one shift for routine maintenance and two shifts ( 16 hours per day) for experimental operation. This schedule will be used five days a week. The weekends will be used for more extensive maintenance, as needed.

We expect to maintain a maximum shot rate of one shot every 5 min during the 13-week experimental operation. Neutron activation of the yin-yang magnets will limit the total duration of high-neutron-producing shots to between 2000 and $3000 \mathrm{~s} /$ week. This will not be a restriction for standard tandem operation, since the maximum shot duration of this mode is expected to be $0.5 \mathrm{~s}$, but will 1 imit the total number of $30-\mathrm{s}$ shots in the thermal-barrier mode. There are three time scales of interest for this mode. The first, on the order of $0.5 \mathrm{~s}$, represents the time required to built up and heat the plasma. The second, on 
the order of 2-5 s, represents the mean equilibration time of the plasma. The final time scale, at least $30 \mathrm{~s}$, is representative of the tiane required to achieve equilibrium with the vacuum and plasme-wall interactions. All experiments designed to investigate phenomena associated with plasma builuup require shots with a total duration of only 0.5-1 s. During these experiments the facility will be operated with both 0.5-s and 20-s neutral-bean sources. The timing of the 0.5-s neutral-beam sources may be staggered to allow machine pulseg longer than $0.5 \mathrm{~s}$. The 30 -s neutral-beam sou.ces and ECRH power will be operated for only 0.5-1 s. Experiments to investigate plasma equilibria require shots in the range of $1-5 \mathrm{~s}$. Thr-a exporiments will be configured in the same manner as the plasma-buildup experiments except that the 30-s neutralbeam sources and ECRH power will be operated for $1-5 \mathrm{~s}$. Only experiments investigating plasma-wall interactions and vacuum equilibria require 30 s shots. We expect to maintain the shot rate of $5 \mathrm{~min} / \mathrm{shot}$, even for the thermal-barrier mode.

Maintaining a shot rate of $5 \mathrm{~min} / \mathrm{shot}$ for the operating cycle described implies a maximum of 35,000 physics shots per year. We expect the average shoi rate to be approximately 10,000 physics shots per year. Additional shots taken during source conditioning will increase the total shot rate to approximately 20,000 shots per year. Conditioning of the $0,5-s$ and 10 -ms neutral beams will be done at a rate of one shot/min. The conditioning scenarios for the $30-\mathrm{s}$ sources and the gyrotror tubes remain to be determined.

The facility will initially be configured for operation in the twocorapnnent standard tandem mode. As the facility is debugged, the operation of the A-cell and ECRH systems will begin, and operation will move into the thermal barrier mode. Thus the initial configuration of the facility must be compatible with both of these modes.

\section{EXPERIMENTAL CONFIGURATION}

\section{A. DEFINITION OF MACHINE REGIONS}

The MFTF-B can be logically subdivided into four separate regions as defined by the axial magnetic-field profile. These regions are shown in Fig. 4. The region extending from the machine midplane to the innermost magnetic field maxima is defined to be the central-cell region. This region 

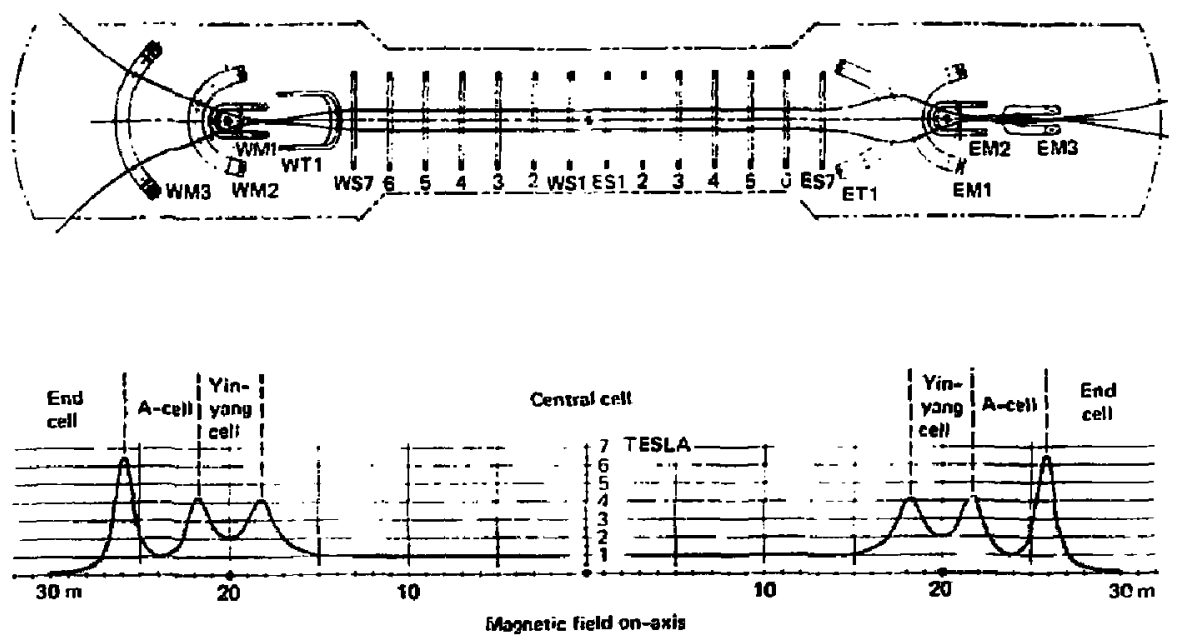

\begin{tabular}{|c|c|c|c|c|}
\hline Uperating mode & $\begin{array}{l}\operatorname{Cen}(r .1] \cos 11 \\
(\operatorname{tog} a b)\end{array}$ & $\begin{array}{l}\text { lin-ying cell } \\
\text { (each end) }\end{array}$ & $\begin{array}{c}\text { A cell } \\
\text { (each end) }\end{array}$ & $\begin{array}{l}\text { End cell } \\
\text { (each end) }\end{array}$ \\
\hline \multicolumn{5}{|c|}{$\begin{array}{l}500 \mathrm{~A}, 15 \mathrm{ked}, \\
10 \mathrm{~ms} \\
600 \mathrm{~A}, 50 \mathrm{kev}, \\
500 \mathrm{~ms}\end{array}$} \\
\hline Twr cumponent & $\begin{array}{l}500-80000 A_{h} \\
\operatorname{cold} \text { gas } \\
300 A, 50 \text { kei } \\
500 \text { ns }\end{array}$ & $\begin{array}{l}500 \mathrm{~A}, 15 \mathrm{keV}, \\
10 \mathrm{~ms} \\
300 \mathrm{Am} 50 \mathrm{keV} \text {. } \\
500 \mathrm{~ms}\end{array}$ & $\begin{array}{l}\text { up to } 50 \mathrm{~A} \\
\text { s0 keV, } 500 \mathrm{~ms}\end{array}$ & $\begin{array}{c}\text { stre eming plasma sources } \\
\left(\bar{n}_{\mathrm{s}} \mathrm{r}^{2} \geq 7 \times 10^{15} \mathrm{ca}^{-1}\right)\end{array}$ \\
\hline \multirow[t]{4}{*}{ Z. Thurrial langrier } & $\begin{array}{c}20-1000 n_{A} \\
\text { cold gas }\end{array}$ & $\begin{array}{l}500 \mathrm{~A}, 15 \mathrm{kaV}, \\
10 \mathrm{~ms}\end{array}$ & $\begin{array}{l}50 \mathrm{~A}, \text { so hav, } \\
\text { SOJ } \mathrm{hts}\end{array}$ & $\begin{array}{l}\text { streaming Fiosma sources } \\
\left(\bar{n}_{\mathrm{s}} \mathrm{r}_{\mathrm{s}}^{2} \geq 7 \times 10^{15} \mathrm{~cm}^{-1}\right)\end{array}$ \\
\hline & $\begin{array}{l}300-400 \mathrm{~A}, 50 \mathrm{keV} \text {, } \\
500 \mathrm{~ms}\end{array}$ & $\begin{array}{l}200-300 \mathrm{~A}, 50 \mathrm{keV}, \\
500 \mathrm{ma}\end{array}$ & $25 A_{3}$ tho keV, & \\
\hline & ${ }_{30}^{25} \mathrm{~A}, 60 \mathrm{keV}$ & $25 \mathrm{~A}, 60 \mathrm{rav}$, & $\begin{array}{l}6 \mathrm{~A}, 2 \mathrm{keV}, \\
30 \text { (LEPB)t } \\
220 \mathrm{~kW} \text { Ear mas } \\
\text { metically crapped } \\
\text { eleetrons }\end{array}$ & $\begin{array}{l}25 \mathrm{~A}, \text { b0 keV, } \\
30 \text { s (HEPB) }\end{array}$ \\
\hline & & & $\begin{array}{l}350 \mathrm{~kW} \text { tor electro- } \\
\text { scaticd1ly } \\
\text { confined electrons }\end{array}$ & \\
\hline
\end{tabular}

Nite: Neutral beam currents are specified as required corrent incident on the plasma.

$\vec{A}_{\mathrm{h}} \quad=$ atubic amperes

tIEPBS = low-energy pump heam

FFF IIElH a hightencrgy putap beain

FIG. 4. Sumary of the machine configuration for MFTF-B. 
includes the field contribution from the transition coils. The region between the magnetic field maxima created ly the yin-yang coils is defined to be the yin-yang region. This region has traditionally been referred to as the plug, hokever, since an electrostatic plug is not ereated in this region for all plasma modes, the nomenclature of the "plug" will not be used here. The region between the two outermost magnetic-field maxima is defines to be the A-cell region (auxiliary cell). Finally, the region from the outermost magnetic-field maxima to the end wall of the vessel is defined to be the end cell.

The MFTF-B program, funded with PACE and operating funds, must provide equipment in four general categories. This equipraent must support the physics requirements in each machine described above for both the standard tandem and the thermal-barrier plasma modes. The machine configuration for each mode will be discussed in this section, and the physics requirements will be discussed in more detail in subsequent sections. The four equipment categories are:

- The equipment necessary to create the required magnetic-field configuration.

- The equipment necessary to control the machine and to obtain, store, and process data about all relevant plasma parameters, including the information necessary to determine particle and power balance in the plasra.

- The equipment necessary to provide the required particle and power fluxes to the plasma, including neutral bears, electron heating (ECRH), gas injection, and streaming plasma sources.

- The equipment (including surface conditioning) necessary to provide a suitable vacuum environment for the plasma.

\section{B. MACHINE CONEIGURATION}

\section{Standard Tandem Mode}

In the standard tandem operating mode, the electrostatic potential well is created solely by a density difference betveen the yin-yang cell and the central cell. The plasma in the yin-yang cell is stabilized against microinstabilities by the warm plasma that is lost axially from the central cell. The confined hot-plasma radius must be at least $20 \mathrm{~cm}$ ot the midplane of the 
yin-yang cell. Energetic neutral beams are required in the central cell, the yin-yang ce1l, and the A-cell. At least $500 \mathrm{~A}$ of $20-\mathrm{kV}, 10-\mathrm{ms}$ startup neutral beam is required in each yin-yang cell. The MFTR $80-\mathrm{kV}, 0.5-\mathrm{s}$ neutral beam sources will be distributed between the central-cell, yin-yang cell, and A-cell. Operation in tinis basic mode without neutral-beam injection in the A-cell is possible, but experiments are planned that require up to $50 \mathrm{~A}$ of sustaining beam in each A-cell. The current required in each yin-yang cell varies from at ieast $300 \mathrm{~A}$ for the two-component mode to as much as $600 \mathrm{~A}$ for simple tandem operation. The facility must be compatible with operation between these limits. The current required in the central cell varies from none in the simple tandem mode to as much as $300 \mathrm{~A}$ for two-component operation. The average energy of the neutral beams must be at least $50 \mathrm{keV}$. A cold-gas current of at least $500 A_{A}$ (atomic amperes) and up to $8000 A_{A}$ is required in the central cell. Sufficient streaming plasma sources are required on each end dome to provide a plasma that satisfies $n_{s} r_{s}^{2} \geq 7 \times 10^{15} \mathrm{~cm}^{-1}$, where $n_{s}$ is the radially averaged streaming-plasma density at the midplane of the yin-yang cell and $r_{s}$ is the streaming-plasma radius at the same location.

\section{Phermal-Barriex Mode}

In the thermal-barrier operating node, the high electrostatic potential is created ty establishing a population of high-temperature electrons in the A-celi. A low-densicy thermal-bartier region must be established between the high-electron-temperature region and the central cell. This thermal-barrier region can be established in either the yin-yang cell (isside barrier), or the $A$-cell (A-cell barrier). The following requirements are specified for h-cellbarrier operation: The confined hot-plasma radius must be at least $40 \mathrm{~cm}$ at the midplane of the $y \perp n$-yang celi. Neutral beams are required in the central cell, yin-yang cell, and A-cell. At least $500 \mathrm{~A}$ of $20-\mathrm{kV}, 10-\pi$ s startup neutral benm is required in each yin-yang cell. Seven $80-\mathrm{kV}, 30-\mathrm{s}$ neutral beams are required to sustain the plasma in this mode. At least 25 a of these neutral beams are required incident on the plasna in each yin-yang cell and in the central cell. At least $25 \mathrm{~A}$ of neutral beam is required incident on the plasma from each end (injected neirly along the magnetic axis) for chargeexchange pumping of the thermal bartier. Each of these beams must have an average energy of at least $60 \mathrm{keV}$. At least 2.5 A of the $80-\mathrm{kV}$ couponent of a 
30-s source must be trapped in each A-cell to establish the sloshing ion distribution. If these bears are injected across the fan on the yin-yang side of the A-cell, we estimate that this requirement can be met with 25 A of neucral beam (average energy $6 \mathrm{C} \mathrm{keV}$ ) incident on the plasma. At least $6 \mathrm{~A}$ of 2-kV, 30-s neutral beam is required in each A-cell to provide charge-exchange pumping. The remainder of the MFTF 80-kV neutra1-beam power supplies (16) are required for 80-kV, 0.5-s sustaining sources in the A-cell, yin-yang cell, and central cel1. These sources provide heating during startup. No more than $50 \mathrm{~A}$ is required in each A-cell. At least $300 \mathrm{~A}$ but up to $400 \mathrm{~A}$ is required in the central cell. At least $200 \mathrm{~A}$ and up to $300 \mathrm{~A}$ is required in each yin-yang cell. The average energy of these neutral beans must be at least 50 keV. At least $20 A_{A}$ and up to $1000 A_{A}$ of deuteriun gas is required in the central cell. At least $220 \mathrm{~kW}$ of ECRH power is required to heat the magnetical. $\mathrm{l}$ g trapped electrons in the barrier and at least $350 \mathrm{~kW}$ to teat the electrons at the electrostatic potential peak in each A-cel1. The streaming plasma requirements for this mode ara the same as for the standard tandem mode. The overall machine configuration for the standard tander and A-cell thermal-barrier operating modes are summarized in Fig. 4. In the case of neutral beams, the required neutral-beam current incident on the plasma is specified together with the required average bear energy. More specific detalls of these requirements are given in the following sections.

\section{v. METF-B MAGNETIC FIELB BEQUIREMENTS}

\section{A. GENERAL REQiIIREMENTS}

The coil set of BifTF-B provides the magnetic field profile necessary to generate the desired plasma parameters. This coil set consists of four subsets (shown in Fig. 5):

\footnotetext{
- Central solenoids.

- Two transition magnets.

- Two yin-yang magnet pairs.

- Two A-cell C-coils.
}

The requirements of these subsets are described in detail later in this section. 


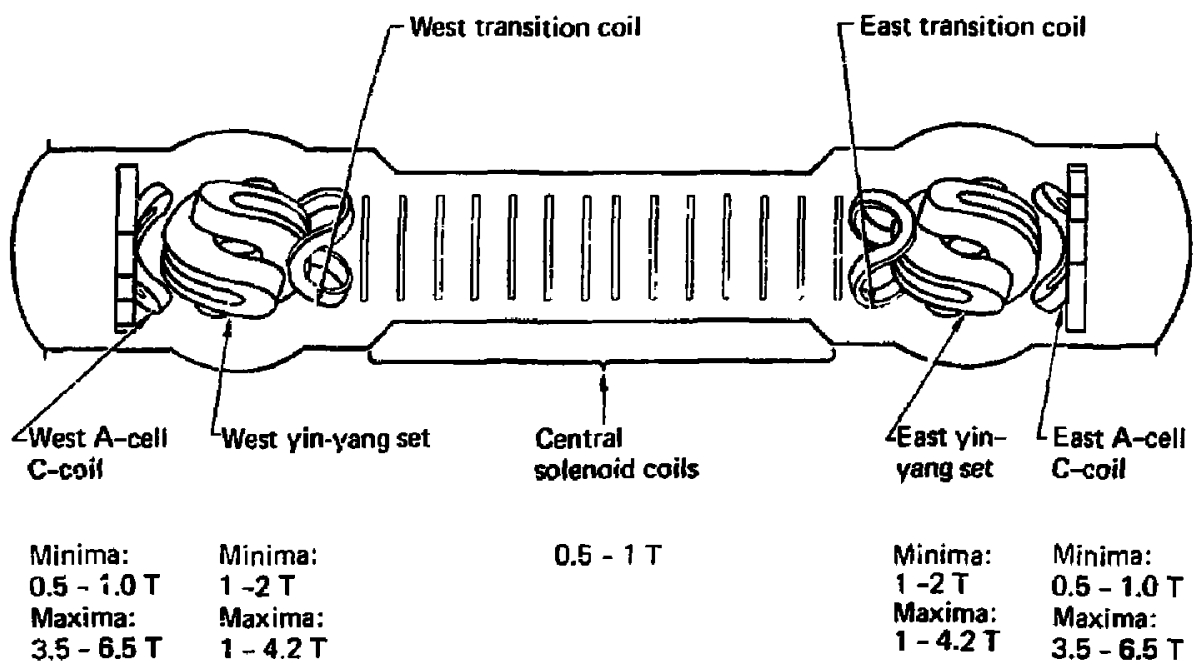

F1G. 5. MFTF-B magnet set.

The requirements for the overall coil set, together with the power supplies, include:

(1) The magnet set mast be sufficiently instrumented to permit accurace datermination of the magnetic field profile.

(2) Direct-current fields must be provided by all magnets.

(3) Overall MHD stability for plasma-density distributions, characterizing both the standard tandem and the thermal-barrier modes of operation, must be provided by the magnetic field profiles. This requirement must be compatible with central-cell plasma betas $\left(\beta_{c}\right)$ in the range $0 \leq \beta_{c} \leq 0.2$.

(4) Adiabaticity must be provided by the field profiles for deuterium ions up to energies of $100 \mathrm{keV}$ in the central cell, $300 \mathrm{keV}$ in the yin-yang region, and $200 \mathrm{keV}$ in the A-cell. These adiabatic energies should be counpatible with operations with plasma betas of at least 0.3 in the central cell, at least 0.5 in the yin-yang cell, and at least 0.4 in the $A$-cell.

(5) Magnet dimensional accuracy and alignment is required so that the magnetic field lines will not be displaced too far from their nominal positions. 
- All displacements and rotations must be small enough to be compatible with the stability and adiabaticity requirements described above.

- Misalignment (both displacement and rotation) must not significantly reduce tine radial transport loss rate.

- The magnet set alignment must permit the use of axial beams for diagnostics and for charge-exchange pumping of thermal barriers.

- A system to measure the orientation of the magnetic axis, under operating condition, must be provided.

(6) Al1 magnet structure must be consistent with the injection of streaming plesma to within a 60 -cm-radius circle at the yin-yang midplane when the yin yang is operated at 2-I central field (mirror ratio of 2.1 ) and the central cell is operated at $0.5 \mathrm{~T}$.

\section{B. CENTRAL-SOLENOID MAGNET COILS}

The solenoid coils contain the central-cell plasma of the tandem mirror cancept. The solenoid roils must be capable of producing an axial magnetic field with the following properties:

- A variable magnitude of 0.5 to at least $1 T$ at the midplane with a maximum azjmuthally symmetric field of $1.2 \mathrm{~T}$ near the transition region.

- Small enough spatial ripple to prevent local mirror trapping, and to be consistent with the plasma confinement parameters. At present, we estimate that a field ripple of $1 \%$ at a radius of $56 \mathrm{~cm}$ with $B=1 \mathrm{~T}$ in the central cell is satisfactory.

In general, to permit flexibility in obtaining field profiles, the solenoid coils must be capable of producing a field which monotonically increases from $0.5 \mathrm{~T}$ at the midplane to $1.2 \mathrm{~T}$ near the trangition coil.

\section{TRANS ITION COILS}

A transition coil is located at each end of the central cell to match the fields of the solenoidal coils and the neighboring yin-yang coil set. 

yin-yang coil set when that coil set is operated at 2-T central field with a mirror ratio of 2 .

The mirror ratio in the A-cell must be 6.5 on axis.

\section{MFTF-B DIAGNOSTIC REQUIREMENTS}

The diagnostics system must support the physies and technology goals of MFTF (both stated in the MFTF-B Project Proposal) and the physics studias in the characterization of tandem mirror machine confinement.

\section{A. DVERALI DIAGNOSTIC SYSTEN REQUIRENINTS}

In support of the goals of MFTF, the diagnostics system must:

(1) Determine ? and correlate it with electrostatic potential well depth. The fusion power output is determined either from the rate of production of $\mathrm{D}-\mathrm{D}$ neutrons, combined with a density or ion-temperature measurement (to determine the equivalent D-T fusion power), or by measuring density and ion temperature independent $1 y$. The measurements must be made in representative sample elements in each of the regions of the machine. A measurement of the power $i_{n p u t}$ to each region then permits a determination of $Q$. The electrostatic well wapth can be obtained by measuring the peak potential in the plug

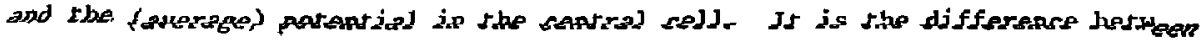
these two potentials that provides the electrostatic confinement, and also limits the $i$ on temperature (and therefore fusion power) of the confined plasma.

(2) Determine radial transport rates and relate them to overall plasma confinement. The radial transport rates will be inferred from detailed measurements of particle balance. Measurement of the radial-density profil and the particle and power inputs at the plasma surface permits modeling of the radial deposition rates of particle and power. Charge-exehange and end losses will be measured directly. The radial transport rates can then be inferred,

Plasma confinement is characterized by the parameters $\mathrm{nt}_{\mathrm{E}}$ (energy) and ${ }^{n} \tau_{P}$ (particle) for each region. $n T_{E}$ may be obtained from the expression

$$
{ }_{T_{E}}=\frac{\pi^{2} r_{i}+F_{e} r^{3}}{P_{i}} .
$$


The volume $V$ and input power $P_{i}$ nust be applied consistently; for example, the volume element may be a flux tube or an entire region. The particle confinement parameter ${ }^{n}{ }_{p}$ is obtained from the relationship

$$
{ }_{n} T_{P}=\frac{n^{2} e L}{J}
$$

where $L$ is the length of the flux tube and $J$ the measured end-loss current.

(2) Determine the microstability of confined plasmas under a variety of operating conditions. Micrninstubilities are characterized by microscopic density fluctuations. Their existence may be inferred from rf radiation, from high-frequency fluctuations on interferometer signals, or from laser or microwave scattering. No single technique will detect all possible fluctuations, so assuring microstability, or detecting the onset of instability, involves several techniques applied over the whole machine. Varied operating conditions means spanning the range from minimum condition for startup to full highdensity high-temperature operation.

(4) Deternine the plasma pressure ( $\beta$ ) in each region, relate it to MHD stability, and measure plasma parameters zelevant to maximizing $B$. The plasma pressure may be inferred from local measurements of density and temperature (bcth elcctron and ion) or an average value may be obtained by measuring the plasma diamagnetism in a region. The central-cell $B$ is of highest importance. parameters relevant to maximizing $\beta$ in the central cell include density, electron and ion temperatures, and electrostatic potential in the other regions, particularly the barrier-plug region.

(5) Monitor the effect of plasma-wall interactions on the plasma during operation. The plassna in the end fan drives gas, cold ions, and cold electrons off the wall and they in turn affect the plasma temperature and potential, usually in a negative way. The emission from the walls, the atomic processes occuring in this region, the background gas pressure, and the effect of the cold plasma load on the hotter region of the plasma must all be monitored.

(6) Measure the amount and character of the "cold load" caused by unatcenuated neutral beams and eharge-exchange fiux, which will generate a flow of gas and cold plasma that will drift out from the walls to the plasma, as well as the effects of the "cold load's" cooling the outer edge of the plasma.

(7) Measure potential profiles, both radial and axial, especially in the thermal-barrier and plug regions. Neasurement of the on-axis profile tells how 
the central flux-bundle operaces, but the overall machine performance will depend on the volume behavior, which in turn will depend on the extent to which radial transport and other off-axis phenomena support or defeat the potential profile.

(8) Determine the essential characteristics of both thermal-barrier operation and standard tandem operation, by measuring the energy distribution and densicy of both electrons and ions and the electrostatic potential in the critical thermal-barrier/plug region.

(9) Audit particle flow and power flow in sufficient detail to support physics modeling. This includes monitoring all sources of input power and particles, measuring or inferring absorbed power of each, and monitoring all power- and particle-loss channels.

(10) Follow the buildup of the plasma and determine the effect on the buildup of various condieions such as background gas pressure, wall refluxing, neutral-bean species' mix, etc.

\section{B. COHPUTER CAPABILITIES REQUIRED}

The adjitional diagnostics required on MFTF-B will require increased capability, over that in process for MFTF, for instrument control, data acquisition, and jata reduction and analysis. Five basic computer-supported activiti:s muit be accommodated for MFTF-B.

(1) On-line, real-time computer control and data acquisition for at least 30 diagnostic instruments, each with an average of 20 channels. Eight million, eight-bit butes of data will be produced per shot every five minutes.

(2) On-line, real-time intershot processing of the 8 megabytes of data. All of the data must be reduced to pilysical units and archived for later analysis. Reduction to physical units means converting the digital output of the diagnostic device to a number which represents the physical parameter being measured, either by using an analytic function or by looking it up in a table. A portion of this reduced data must be displayed in both hard and soft copy as either tables or graphs with time as the independent variable. The portion of data to be displayed must be selectable by the experimental leader. In addition, a subset of the data, to be selectable by the experimental leader, must be reduced to obtain the desired plasma parameters which can be displayed in either tabular or graphical form. Processed data from at least 100 shots must 
be readily availabie so that a selected set of parameters from the last shot can be compared with previous shots within the available intershot time.

(3) Batch processing to reduce all data obtained in the previous day to plasma parameters and to generate hard-copy tables and graphs of the results. Some of these plasma parameters must be archived.

(4) Quasi-real-tine analysis of the MFTF-B data base. Sophisticated analysis of the data base in the context of theory development and verification will be part of this activity. at least five people must be accommodated so that they can work simultaneously, in near real time. Both time-shared and batch-processing modes should be provided.

(5) Off-line, quasi-real-time applications-program development, as it specifically relates to plasma diagnostics activities assuming five programmers working simultaneousiy. Facilities should be provided that will ensure that program debug can be accomplished off-line.

\section{INITIAL DLAGNOSTIC SYSTEM REQUIRENENTS}

The requirements listed above are for the running period of the facility. It is recognized that, primarily for budget reasons, it will not be possible ta Inake all necessary measurements simultaneously, nor will the set of instruments that is on the machine at the completion of construction be the final sel. Nonetheless, it is a cequirement that the initial diagnostic system be capable of measuring minimum characteristic plasma $p e r$ ers in order to facilitate initial machine startup, and making enough measurs ents of plasma confinement in the initial physics experiments to permit a overall assessment of the performance. It must also be expandable to the larger system described above.

To meet the task of facilitating initial startup, the diagnostics system must be able to:

- Measure low plasma densities and temperatures in the central cell, both yin-yang regions, and both A-cells.

Measure reduced end-loss currents.

- Determine local neutral gas densities in the central cell, yin-yang cells, and A-cells. 
The second requirement of the initial diagnostics system is to confirm confinenent behavior and/or identify the elements preventing expected operation. This implies making characteristic measurements (i.e., averages or single point measurements, rather than detailed profiles) of:

- Central-cell confinement ( $n)_{e}$.

- Plasma density and electron temperature in both yin-yang regions.

- Plasma density and electron temperature in the region of maximum electrostatic potential.

- Plasma density and average ion energy in the region of minimum electrostatic potential.

- Maximum electrostatic potential.

- MHD stability.

- Microstability.

The third requirement means that the design of the initial system must not preclude addition of instruments, increase in channels, or increase in reta-processing and analysis load, but rather, wherever pussibla, accomodate the expansion simply by addition of hardware. Thus, the system for daca acquisition, processing, analysis, display, and archiving must be designed with the completed system in mind, even if not all the hardware is included in the construction phase. The vessel ports, plasma access, space frame, mechanical support, utilities, and space outside the vault must acconmodate the completed system.

\section{MFTF-B PARTICLE AND ENERGY SOURCE REQUIREMENTS}

Production of the hot plasma for all confinement experiments in MFTF-B requires a system of plasma-stream guns to produce an initial plasma target, neutral beams for building and sustaining the hot plasma, an ECRh system for local electron heating, and a gas-injection system for plasma stabilization and/cit fueling.

\section{A. STREAMING-PLASMA-GUN SYSTEM}

The streaming-plasma system must be capable of producing a plasma with a redially averaged densicy, $\bar{a}_{s}$, which satisfies the condition 
$\pi_{s} r_{s}^{2} \geq 7 \times 10^{15} \mathrm{~cm}^{-1}$

at the midplane of each yin-yang cell. The parameter $I_{s}$ is the streaningplasma radius and must be as large as $60 \mathrm{~cm}$ for buildup of a 40 -cm-radius hot plasma. The uniformity of this plasma must be consistent with the buildup of a hot plasma by neucral-beam injection.

B. NEUTRAZ-BEAM SYSTEM

The neutral-beam system required for MFTF-B was discussed briefly in Sec. IV. These beams can be classified into four categories, based on their use in the facility:
- Startup neutral beams.
- Heating/sustaining neutral beans.
- Sustaining neutral beans.
- Charge-exchange pumping neutral beams.

Startup neutral beams are intermediate energy (nominally 20-kV extraction), short-pulse-length (nominally 10-ms) beams used in the yin-yang cells to make the transition from an unconfined streaming plasma to a mirror-confined hot plasma. These beams serve the same function for both the standard tandem modes ard the thermal-barrier mode. Heating/sustaining neutral beams are high-energy (nominally 80-kV extraction), intermediate-pulse-length (nominally 0.5-s) beams. They are used to heat and sustain the plasma in the central cell and rin-yang cells in the standard tandem modes. They can also be used to estabLish a mirror-confined plasma in the A-cell for these modes. Their primary function in the thermal-barrier mode is to heat the plasma in the central cell and yin-yang cells and to establish the sloshing-ion distribution in the A-cells. Sustaining newtral beams are high-energy (nominally 80-kV extraction), long-pulse-length (nominally 30-s) beans. They are used to sustain the plasma in the central cell, yin-yang cells, and A-cell in the thermal-barrier mode. Charge-exchange pumping neutral beams provide the ion pumping required in the A-cell thermal-barrier mode. These beams have a long pulse length (nomina1ly $30 \mathrm{~s}$ ), and include boch the low-energy pump beata (LEPB--nominally 
2-kV extraction) and the high-energy pump beam (HEPB--nominally 80-kV extraction).

The neutral-beam system must be capable of providing the required neutral-beam current to the plasina for both the standard tanden modes and the thermal-barrier mode. These currents are specified in Sec. IV.

The focusing and divergence properties of all neutral beams must be consistent with providing the required total beam current as well as providing the required beam-current profile incident on the plasma. They must also be compatible with the vacuun requirements to be specified later.

The aiming flexibility of all neutral-beam modules must be -nnsistent with providing the required team-current profile incident on the plasma.

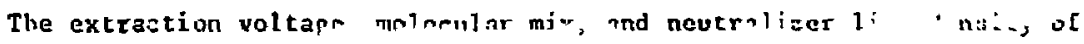
each neutral bejm must be compatible with providing the average beam energies specified in Sec. IV.

To avoid impurity problems in MFTF, the impurity particle flux (species other than deuterium) in the heating/sustaining neutral beams must be no more than 0.3\% of the deuterium particle flux. Likewise, the impurity flux of the sustaining and charge-exchange-pumping neutral beams in the A-cell must be no more cluan $0.1 \%$ of the deuterium flux.

A11 neutral-beam 1 ines must be compatible with both the conditioning shot cycle and the physics sitt cycle as discussed previously in Ser. III D.

C. ELECTRON CYCLOTRON RESOHANCE HEATING (ECRH)

Electron heating is required to establish the correct potential profile for the therual-barrier mode; it is also needed for electron-heating experiments in other operational modes. The heatiry method is absorption of microwave radiation energy-usually at the fundamental electron-cyclotron resonance frequency. Because existing high-power microwave tubes operate at a fixed frequency, it is useful to define the resonant magnetic field $B_{R}$ corresponding to each microwave frequency used. For the existing 28-GHz gyrotrons (wavelength $1.07 \mathrm{~cm}$ ) the resonant field $B_{R}=1 \mathrm{i}$. For a resonant field of $2 \mathrm{~T}$, we require a $56-\mathrm{GHz}$ gyrotron (wave length, $0.535 \mathrm{~cm}$ ). The corresponding fields at the second harmonic resonance are $0.5 \mathrm{~T}$ and $1.0 \mathrm{~T}$, respectively. For some experiments, a two-frequency microwave combination is needed, where the second frequency is 5 to $10 \%$ lower than the normal one. Such a 
combination has been demonstrated to have an enhanced heating effect over a single frequency. Furthermore, as the plasma beta increases, the local magnetic field decreases, and the resonant frequency near the center of the plasma drops to a lower value.

For MFTF field gradients and electron temperatures, the efficiency of alisorption of the mi'ruwaves is predicted to approach $100 \%$ at the resonant surface for the extraordinary wave polarization. The ordinary wave is efficiencly absorbed at high electron temperaturss, but this efficiency drops somewhat at low temperatures. However, a more important inefficiency is believed to arise from beam-aiming problems-the matching of the antenna radiation pattern to the ray trajectories that lead to the resonant absorption region. The calcuiation of this coupling is an ongoing problem.

In each A-ce11, the power required to magnetically trap the electrons is $220 \mathrm{~kW}$ at either 28 or $56 \mathrm{GHz}$ or a combination of the two. At or near the $B=2 T$ resonance surface near the $C-c o i l$, the electron heating requirement in each $\mathrm{A}-\mathrm{ce} 1 \mathrm{l}$ is $350 \mathrm{~kW}$. These numbers encompass only the predicted electron losses from the plasma, such as collisional drag and synchrotron radiation. They do not include such effects as incomplete absorption of the microwaves in the plama, misdirected antenna patterns, and waveguide losses in the windows, the joints, the bends, etc.--all of which will require additional power.

It is required that each antenna be lacated in a high-field region ( $B>B_{R}$ ) in order to ensure that the extraordinary wave will have access to whe resonant layer without encountering a plasma cutoff. All of the waveguide equipment must be operable at any frequency in the range $28-60 \mathrm{GHz}$.

The power output of the ECRH system is required to be programable in time with a time constant in the range of 100 milliseconds.

Instrumentation is required to detemine radiated microwave power from each gyratron tube and is associated wave guide and antenna system.

\section{THE GAS-INJECTION SYSTEM}

Room-temperature gas must be introduced into the central cell to fuel the central-celi plasma. The quantity of gas required is dependent on the operating mode, and varies from at least $20 \mathrm{~A}_{\mathrm{A}}$ (atomic amperes) of room temperature gas for the A-cell thermal-barrier mode up to $8000 \mathrm{~A}_{A}$ for the standard tandem modes. The gas-injection system must be continuously 
adjustable between these limits. For the standard tandem modes, the gas-injection system must provide sufficies: central-cell plaswa to stabilize the yin-yang cells against the DCLC mode.

Two types of gas feed must be provided. In the first, the neutral gas must be localized in a small axial region near the magnetic maximum between the yin-yang cell and the central cell (both ends). The injected gas density must be uliform within $\pm 10 \%$ over the plasma surface in this region. In this case the neutral gas pressure in the central cell must be minimized, and will requice apertures which fit closely around the plasma fan. These apertures must be capable of being aligned with the magnetic field, to limit the unionized gas which escapes to the central cell and yin-yang cells to less than $1 \%$ of the injected gas. This type of gas feed is referred to as gas-box injection. The second type of gas feed requires gas flow to the plasma along the entire length of the central cell. In this case we require a uniform gas density (within $\pm 10 \%$ ) both arimuthally and axially over the plasma surface. This type of gas feed is referred to as gas-blanket injection. In both cases we require sufficient instrumentation to determine the gas current injected into the vesse1. The gas control must be capable of modifying the gas current on a time scale of $100 \mathrm{~ms}$.

\section{VIII, MFTF-B VACUUM REQUIREMENTS}

The overall vacuum requirement is. MFTF-B is that the cold gas environment must not inhibit the planned operating modes of the plaska. This requirement has different implications for each cell of the facility. In general, the vacuum requirements can be subdivided inta base vacuum requirements and plasma vacuum requirements.

\section{A. BASE VACUUM REQUIREMENTS}

The base vacuum is defined to be the neutral-gas density which exists in the MFTF-B vacuum vessel immediately before a plasma shot is initiated. In all cells, in the region to be occupied by plasma, this gas density must be sufficiently less than the gas density expected during a plasma shot that the base yacuum has no effect on the plasma parameters. Furthermore, the impuxity concent supplied by the base vacuum must be sufficiently low that the amount of 
contaminant desorbed from surfaces that view the plasma does not produce radiation losses greater than $10 \%$ of the power input to the plasma. This requirement also applies to concaminants deposited on surfaces during atmospheric pump-dowt .

\section{B. PLASNA VACUUM REQUIREMENTS}

The plasma vacuum requirements are different for each cell and depend on the operating mode. In all cases, however, the plasma vacuum is deternined by a balance between gas sources and available pumping. six gas sources have bcen identified:

- Gas injection system.

- Base vacuum.

- Cold gas from the neutral beam injectors and plasma streaming system.

- Cold gas refluxing from the neutral bean and ion dumps.

- Cold gas (and contaminants) desorbed from surfaces that view the plasma.

- Higher $Z(Z>1)$ atoms sputtered from curfaces exposed to energetic particles (e.g., neutral beam dump, system surfaces).

\section{Central Cell}

During plasma operation, the quantity of fuel gas $(2=1)$ introduced by all sources other than the gas-injection system must be less than the minimum required to supply particles to the plasma. The quantity of contaminants introduced to the plasua unust be sufficiently low that radiation losses are less than $10 \%$ of the total energy losses in the central cell.

\section{Yin-yang $\mathrm{Cel1}$}

The main effect of cold gas in the yin-yang cell is the erosion of the plasma surface by charge-exchange reactions. During operation, the neutral-gas density must be low enough so that the desired plasma can be created and maintained with the available neutral-beam injectors. $m: 9$ desired plasma radius 
at the midplane of the yin-yang sell is $40 \mathrm{~cm}$ in the thermal-barrier mode and $20 \mathrm{~cm}$ in the standard tandem made.

\section{A cell}

In the A-cell region, neutral particles ionized in the plasma core are electrostatically trapped. This plasma fills in the electrostatic well, thus reducing any advantageous thermal-bartier effects. The criteria for acceptable neutral-particle density in the plasma core is that the filling of the electrostatic well by ionization of neutrals must be insignificant compared to the fill rate by collisional trapping of the passing plasma particle distribution.

The rate of filling by ionization of neutrals is determined by the coldgas density at the plasma boundaxy and the transmission factor for neutral particles through a halo plasma created by gas injection in the center cell. Both a low cold-gas density and a low halo transmission of neutrals will be required to meet these criteria.

\section{End Cell}

There are three sources of power loss in the end cell:

(1) Ionization of cold-gas ions resulting in:

- Energy lost in ionizing cold-gas molecules.

- Energy last when ions fail down the positive potential hill to the end wall.

(2) Energy required to heat the electrons resulting from the ionization of cold gas.

(3) Energy lost during ion- and electron-induced secondary-electron enission:

- Exchange of cold electrons for hot, as required by charge neutrality.

- Heating of the cold secondary electrons. 
All three loss processes are influenced by cold-gas density: (1) and (2) are a direct result of the gas density while (3) is enhanced by the presence of a cold plasma created by ionization of the gas.

Although the tatal power lost to the end wall is largely constant (assuming axial loss is larger than radial loss), the primary effect of the three sources of power loss noted above is to teduce the electron temperature and hence the confinement qualities of the plasma.

Recycling of deuterium or contaminants will exponentially increase the cold-gas (and hence cold-plasma) density. Therefore, the condition of the exposed surfaces and dynamic processes during the plasma pulse are most important. The recycling coefficient for both energetic (E $>1 \mathrm{keV}$ ) and cold $(E<1 \mathrm{keV}$ ) deuterium must be low enough to prevent deterioration of the electron temperature. The maximum al:awable value of cold-gas density must be low enough that the cold-gas ionization and secondary electron processes do not unduly increase the power loss in the electron channel over ideal conditions. Finally, the vacuum system must provide sufficient pumping in the vicinity of the neutral-beam sources to minimize the loss of neutral beam due to reionization by gas. The local vacuum must be compatible with the total neutral-bean current requirements . 
REFERENCES

1. Thomassen, K. I., and Karpenko, V. H., Tanden Mirror Fusion Test Facility, MFTF-B, Conceptual Design Report and Project Proposal, Lawrence Livermore National Laboratory, Livermore, CA, LLL-PROP-163, Rev, 1 (1980).

2. B. E. Baldwin, B. G. Logan, and T. C. Simonen, Physics Basis for MFTF Lawrence Livermore National Laboratory, Livermore, CA, UCID-1B496-Part 1 (1980).

3. J. W. Shearer, Estimation of Neutral-Bear-Induced Field Reversal in MFTF by an Approximate Scaling Law, Lawrence Livermore National Laboratory, Livermore, CA, UC ID-18615 (1980). 